\section{Efficacy and limitations of different approaches to anticipate the diagnosis of pregnancy in cattle}

\author{
[Eficácia e limitações de diferentes abordagens para antecipar o diagnóstico \\ de gestação em bovinos] \\ M.P. Palhão ${ }^{1}$, C.R.B. Guimarães ${ }^{1}$, J.F.J.F.M. Lima ${ }^{1}$, M.R. Mendonça ${ }^{1}$, \\ C.A.C. Fernandes ${ }^{2}$, J.P. Neves ${ }^{1}$, J.A.D. Garcia ${ }^{1,3}$, M.M. Gioso ${ }^{1}$, \\ M.A. Miglino ${ }^{4}$, J.H.M. Viana ${ }^{5}$ \\ ${ }^{1}$ Universidade José do Rosário Vellano - Alfenas, MG \\ ${ }^{2}$ Biotran Biotecnologia Animal LTDA - Alfenas, MG \\ ${ }^{3}$ IFSuldeMinas - Machado, MG \\ ${ }^{4}$ Universidade de São Paulo - São Paulo, SP \\ ${ }^{5}$ Embrapa Recursos Genéticos e Biotecnologia - Brasília, DF
}

(t): //orcid org/0000-0002-8779-3837

C.A.C. Fernandes

https://orcid.org/0000-0003-1764-7866 J.P. Neves

https://orcid.org/0000-0001-7733-869X J.A.D. Garcia

https://orcid.org/0000-0002-4024-3045 M.M. Gioso

https://orcid.org/0000-0002-7841-492X M.A. Miglino

https://orcid.org/0000-0003-4979-115X J.H.M. Viana

https://orcid.org/0000-0002-3742-2368

\begin{abstract}
The study evaluated sonographic and serologic exams performed for early (20 to 30d) diagnosis of pregnancy. One hundred-twenty $(n=120)$ bovine recipients were synchronized (estrous=D0) and timed embryo transferred (TET, D7) with fresh in vitro produced embryos. In the first trial $(\mathrm{n}=46)$, diagnosis of pregnancy was performed on day 20 (D20) by detecting CL blood flow (BF) and by PregnancyAssociated Glycoproteins (PAGs) serology. In the second trial $(n=30)$, pregnancy diagnosis was performed on D25 by ultrasound visualization of uterine contents and by PAGs serology. In the last trial, PAG's serology was performed on D30. Ultrasonographic detection of the uterine contents and embryo viability performed on D30 (DG30) was considered the gold standard. The PROC FREQ procedure was used to test the agreement between diagnostic methods. On D20, the Doppler ultrasonography of the CL had showed high sensitivity $(100 \%)$, but only moderate specificity $(53.3 \%)$. On the same day, serologic diagnostic had no agreement $(\mathrm{k}=-0.08, \mathrm{P}<0.46)$ with the gold standard, with very low sensitivity $(6.3 \%)$. However, the sensitivity of the serologic exam increased dramatically (from 6.3 to $100 \%$ ) from D20 to $\mathrm{D} 25$, and it contributed to detect false negatives from the ultrasound diagnosis, improving the overall accuracy from $90 \%$ to $96.7 \%$.
\end{abstract}

Keyword: color doppler, PAGs, timed embryo transfer

\title{
RESUMO
}

O estudo foi planejado para correlacionar exames ultrassonográficos e sorológicos realizados para o diagnóstico precoce $(20$ a 30d) de gestação. Cento e vinte $(n=120)$ receptoras bovinas foram sincronizadas (estro $=D 0)$, e embriões frescos produzidos in vitro foram transferidos em tempo fixo (TETF, D7). No experimento $1(n=46)$, o diagnóstico de gestação foi realizado no D20, pela detecção do fluxo sanguíneo do $C L$ e pela sorologia de glicoproteinas associadas à gestação $(P A G s)$. No experimento $2(n=30)$, a detecção da gestação foi realizada por meio da visualização do conteúdo do útero e também pela sorologia para PAGs. No experimento 3, a sorologia para PAGs foi realizada no D30. Em todos os experimentos, a visualização ultrassonográfica da vesícula e da viabilidade embrionária, realizada no D30, foi considerada padrão-ouro. $O$ procedimento PROC FREQ testou o nível de concordância dos métodos diagnósticos. No D20, o diagnóstico baseado na vascularização do CL mostrou alta sensibilidade (100\%) e apenas moderada especificidade $(53,3 \%)$. Nesse mesmo dia, o diagnóstico sorológico não apresentou concordância $(k=-0,08, P<0,46)$ com o padrão-ouro, além de baixa sensibilidade (6,3\%). No entanto, a sensibilidade do exame sorológico aumentou drasticamente (6,3 para 100\%) do D20 para o D25, contribuindo para detectar falsos negativos diagnosticados pela ultrassonografia, melhorando a acurácia (90 para $96,7 \%$ ).

Palavras-chave: Doppler colorido, PAGs, transferência de embriões em tempo fixo

Recebido em 10 de abril de 2018

Aceito em 25 de janeiro de 2019

E-mail: millerpalhao@yahoo.com.br 


\section{INTRODUCTION}

The early identification of pregnancy after artificial insemination (AI) or embryo transfer (ET) is an important strategy to reduce parturition interval and increase reproductive efficiency of the herd (Diskin et al., 2012; Siqueira et al., 2013; Guimarães et al., 2015; Pohler et al., 2015; Pohler et al., 2016a; Pohler et $a l ., 2016 \mathrm{~b})$. In reproductive management, early detection of non-pregnant cows allows rapid reinsemination of those who failed to conceive or, alternatively, culling of unproductive animals.

The evolution of diagnostic methods has contributed to an increasingly earlier diagnosis of pregnancy. Rectal examination of the uterus, starting 30 days after mating, has long been used to diagnose pregnancy in cattle (Lucy et al., 2011). At the beginning of the gestation, the main criteria in this method is uterine horn asymmetry and its accuracy increases after 40 days. The ultrasonography was a major advance in pregnancy diagnosis, as it allows the direct visualization of the embryonic vesicle from day 23 to 26. However, the accuracy of ultrasonography is dependent on the experience of the technician, and it is consistently higher from day 30 (Beal et al., 1992).

Several chemical and biochemical markers can also be used as indicators of pregnancy or nonpregnancy. Estrone sulfate, for example, is a steroid hormone produced by the fetus that can be detected in the serum of the pregnant female from 100 days of gestation (Holdsworth et al., 1982). Another marker is the Early Pregnant Factor (EPF), which can be detected in the bloodstream as early as $48 \mathrm{~h}$ after the mating (Cordoba et al., 2001). However, this test is prone to many false-positives, probably due to early pregnancy losses, and the high costs prevents its commercial use.

Progesterone analysis can be used for the detection of non-pregnant cattle. The absence of pregnancy is evidenced when low concentrations of progesterone are detected during the period that comprises the end of the cycle (luteolysis) and beginning of a new one (luteogenesis). It is a common chemical test, commercially available, although it is not largely routinely used (Pohler et al., 2016a,b). However, major differences in progesterone profile (high or low) can be indirectly inferred by the evaluation of corpus luteum (CL) vascularization using color Doppler ultrasonography (Ginther et al., 2009). Recently, this technique was successfully used for the early identification of non-pregnant cattle 20 days after artificial insemination (Siqueira et al., 2013) or 14 days after embryo transfer (Guimarães et al., 2015).

The detection of Pregnancy-associated Glycoproteins (PAGs) has become another alternative to early pregnancy diagnosis. The trophoblastic bi-nucleated cells (BNC) produce these glycoproteins in order to attach the chorioallantoic membrane to the endometrium (Pohler et al., 2015). Part of these glycoproteins reache the bloodstream and a significant increase in maternal plasma concentrations occurs between 22 and 24 days of gestation (Green $e t$ al., 2005). The maternal levels of these glycoproteins are variable, and a peak concentration occurs around mid gestation, when it starts to fall and declines until birth, although detectable concentrations are present for a few days after parturition (Constant et al., 2011).

This study evaluated ultrasound technics and PAGs serology performed for early pregnancy diagnosis $(20$ to $30 \mathrm{~d})$ in bovine embryo recipients. Our hypothesis is that the detection of the PAGs, in association with the use of ultrasound, can increase the accuracy of early pregnancy diagnosis.

\section{MATERIALS AND METHODS}

For this study Nelore cows (Bos taurus indicus) were used as embryo recipients. These animals were kept extensively on a grazing system (Brachiaria brizanta), under a stocking rate of $1.0 \mathrm{animal} / \mathrm{ha}$ and under the same environment conditions of light and temperature, during the rainy season. The animals received a complete mineral mixture supplement and had free access to water throughout the experimental period. All experimental procedures were previously approved by the Ethics Committee for animal use of the Universidade José do Rosário Vellano - UNIFENAS (Protocol-UNIFENAS 9A/2016).

Three independent trials were performed to evaluate the accuracy of ultrasonography and of serology for PAGs as isolated and complementary tools to diagnose early 
pregnancy in cattle. In all trials the recipients underwent the same hormonal protocol for the synchronization of estrus and ovulations. Starting on day -10 (D-10, the expected estrus was defined as D0) all animals received an intravaginal progesterone device $(0.75 \mathrm{~g})$ and an IM injection of $2 \mathrm{mg}$ estradiol benzoate (EB). On D-2 the intravaginal device was withdrawal and $0.15 \mathrm{mg}$ D-cloprostenol, 25IU follicle stimulating hormone (FSH/LH), and $0.5 \mathrm{mg}$ estradiol cypionate (EC) were injected IM. The estrus of the recipients was expected to occur synchronously with the recovery at slaughterhouse of the cumulus-oocyte complexes (COCs) used for in vitro embryo production (IVEP). Seven days later (D7), each recipient was examined by rectal palpation for $\mathrm{CL}$ presence and size. The animals with a large- or medium-size CL received a fresh embryo, which was placed non-surgically in the uterine horn ipsilateral to the CL.

After embryo transfer, the recipients $(\mathrm{N}=120)$ were assigned to one of the following trials: Trial 1, Diagnosis of pregnancy based on CL blood flow and serologic detection of PAGs performed on day $20(\mathrm{~N}=46)$; Trial 2, Diagnosis of pregnancy based on detection of the embryonic vesicle and serology for PAGs on day $25(\mathrm{~N}=$ 30); and Trial 3, Diagnosis of pregnancy based on embryo detection and serology for PAGs on day $30(\mathrm{~N}=44)$. For trials 1 and 2 , the animals were subsequently checked for embryo detection on day 30 , which was considered as the "gold" standard reference for pregnancy. In trial 3, the efficiency of serological diagnosis was compared directly with the gold standard. The experimental design is summarized in Figure 1.

Trial 1

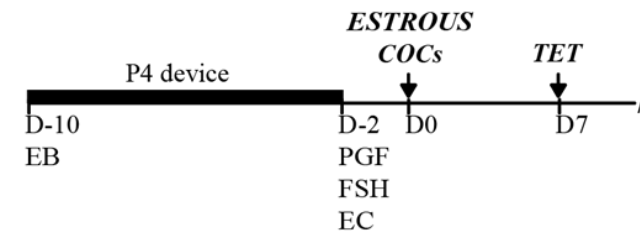

DG20

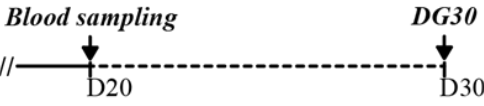

EC DG25

Trial 2

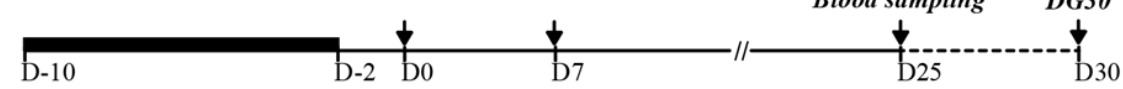

Trial 3

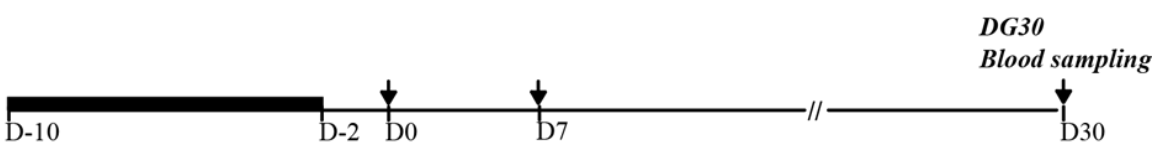

D - Experimental Day related to estrous or COCs recover, considered as day 0 (D0).

EB - Estradiol Benzoate ( $2 \mathrm{mg}$, to synchronize follicle development).

P4 device - Intravaginal progesterone implant $(0.75 \mathrm{~g})$.

PGF - Prostaglandin injection (0.15mg of D-cloprostenol).

FSH - Follicle Estimulating Hormone (25UI).

EC - Estradiol Cipionate (0.5mg to synchronize estrous and ovulation).

ESTROUS - Approached day for estrous behavior of the synchronized recipients.

COCs - Cumulus oocyte complexes recovered from slaughterhouse ovaries.

TET - Timed Embryo transfer.

DG - Pregnancy diagnostic based on CL blood flow (DG20), visualization of the

embryonic vesicle (DG25) and based on embryo inspection (DG30).

Blood sampling - for serologic inspection of PAGs.

Figure 1. Experimental design for early pregnancy check in bovine embryo recipients.

Embryos were produced in vitro following the standard protocol of a commercial IVEP laboratory (Biotran, LTDA, Alfenas, MG, Brazil). Ovaries of crossbreed animals were collected at slaughterhouse and kept in $0.9 \%$ saline $(\mathrm{NaCl})$ solution at 35 to $37^{\circ} \mathrm{C}$ during transportation. In the laboratory, follicles with 2 to $8 \mathrm{~mm}$ in diameter were aspirated, using $10 \mathrm{~mL}$ disposable syringes equipped with $18 \mathrm{G}$ needles, and the COCs recovered were used to in vitro maturation, fertilization, and subsequent embryo culture under controlled conditions $\left(38.5^{\circ} \mathrm{C}, 5 \%\right.$ 
$\mathrm{CO} 2$ and $95 \%$ humidity atmosphere). Semen from a single Nelore breed bull, with previous record of good fertility, was used for fertilization. On day 7, blastocysts (BL) or expanded blastocysts (BX) classified as quality grade I (according to the manual of the International Embryo Transfer Society, 2010) were selected to be transferred. Embryos were kept in holding media at $37^{\circ} \mathrm{C}$ until transfer.

In trial 1 , the CL blood flow was evaluated by color Doppler ultrasonography on day 20 (DG20) of the expected pregnancy (i.e., 13 days after embryo transfer), as previously described (Guimarães et al., 2015). In trial 2, B-mode ultrasound was used to visualize the embryonic vesicle inside the uterine horn ipsilateral to the CL on day 25 (DG25). For the gold standard, Bmode ultrasound was used to visualize the embryo itself, as well as its heartbeats, on day 30 (DG30). All transrectal ultrasound examinations were performed using a $7.5 \mathrm{MHz}$ probe (M5, Mindray, DPS medical equipment, São Paulo, SP, Brazil).

For the serological diagnosis of pregnancy, boPAGs (bovine PAGs) were directly detected in plasma using an immunoenzimatic assay (ELISA). Blood samples were collected by puncture of the coccygeal artery or vein, immediately after ultrasound evaluations performed on days 20,25, or 30 (trials 1, 2, and 3 , respectively, and for the gold standard). Blood samples were kept in tubes with EDTA and stored at $4^{\circ} \mathrm{C}$. Plasma was obtained by centrifugation at $600 \mathrm{G}$ for 10 minutes, and $1 \mathrm{~mL}$ was stored at $-20^{\circ} \mathrm{C}$ until further analysis.

The immunoenzymatic assay was performed with a commercial kit (IDEXX ${ }^{\circledR}$ - Rapid Visual Pregnancy Test) containing conjugated enzyme, specific antibody (anti-PAG), reference standards (negative and positive); enzymatic substrate and wash solution. After dilution and incubation of the samples, positive samples form enzyme-antibody-PAG complexes. After washing, the enzymes that did not form the complex were extracted from the system. The final concentration of the enzyme is directly proportional to the concentration of the glycoproteins present in each sample. The subsequent enzymatic action after substrate addition promotes change in the color of the solution. Samples were considered as from pregnant cows when the coloring tone of the solution was equal or greater than the observed in the positive standard.

In all experiments, the ultrasound examination performed on day 30 (DG30) was considered the gold standard reference. Data from ultrasound and serological diagnosis performed for the 3 trials were analyzed by the statistical procedure PROC FREQ and represented in correlation charts, showing the level of agreement - Kappa (k) - between the tests, with its confidence interval (95\%). In trials 1 and 2, ultrasound and serological diagnosis were confronted with the gold standard reference. In experiment 3, the correlation chart and the Kappa statistic were performed to detect the level of concordance between the serology and DG30. Confidence interval of $95 \%$, represented in each figure, was built to place Kappa variation. All procedures were carried out in the statistical software SAS version 9.4, accessed through SAS virtual University Edition.

\section{RESULTS}

In the first trial, pregnancy diagnosis based on CL blood flow (DG20) showed a moderate degree of agreement $(\mathrm{k}=0.44, \mathrm{P}<0.0003)$ with DG30 (Figure 2A). The negative predictive value of $100 \%$ represents the absence of false negative results. However, the positive predictive value of $53.3 \%$ was due to false positive results, and it is represented in Figure 2A by the gray areas above the diagonal dash line. On this same gestational age, serological diagnosis by PAGs detection had no agreement $(\mathrm{k}=-0.08, \mathrm{P}<0.46)$ with the results of the gold standard reference (DG30). This test showed low sensitivity $(6.3 \%)$ to detect positive animals on day 20 (Figure 2B).

When performed on day 25, both B-mode ultrasound and PAGs detection showed a high degree of agreement $(\mathrm{P}<0.0001)$ with the gold reference (Kappa of 0.80 and 0.86 for ultrasound and serology of PAGs, respectively). However, the sensitivity of the ultrasonography was $88.2 \%$, due to the occurrence of two false negative diagnoses - gray areas below the diagonal dash line (Figure 3A). Otherwise, the serology PAG was $100 \%$ sensitive, not showing false negative results, but 2 false positive diagnoses were observed (Figure 3B). 

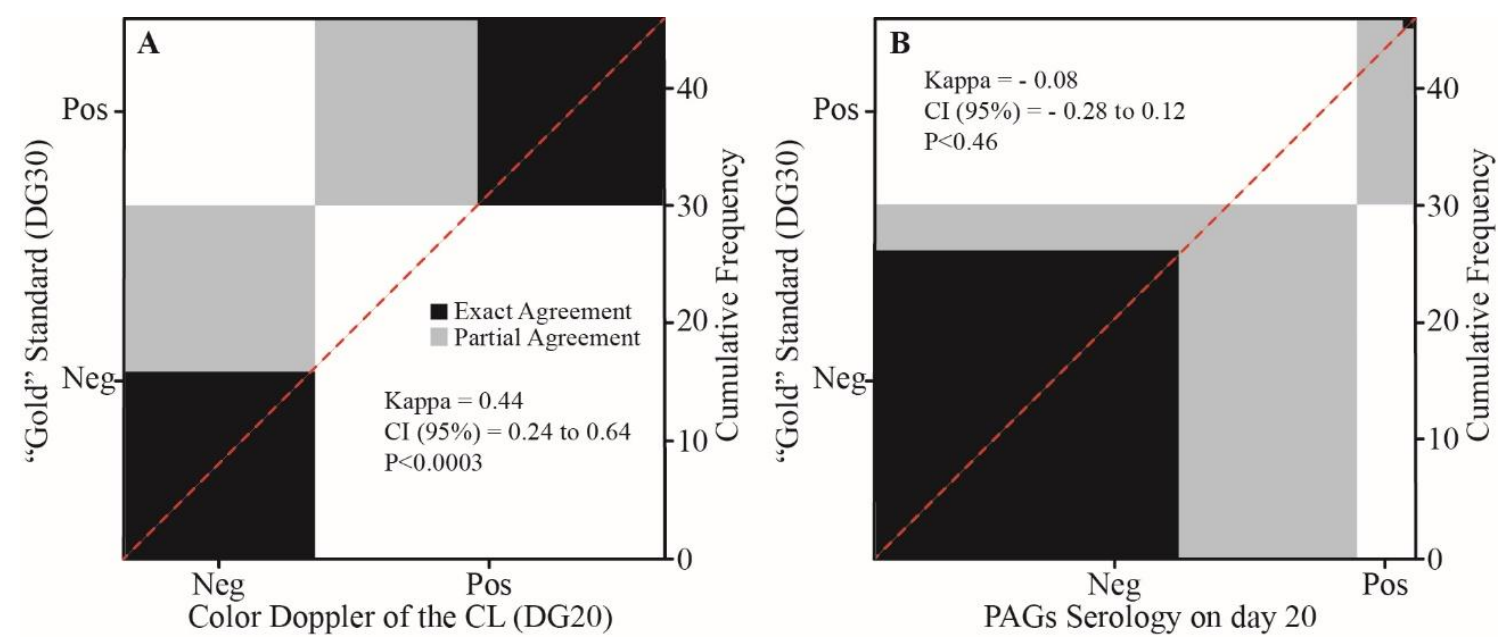

Figure 2. Correlation chart of the pregnancy diagnosis based on color Doppler of the CL (Figure 2A) and PAGs serology (Figure 2B) performed at day 20 (DG20) of the expected pregnancy of bovine embryo recipients. In each chart, the black squares represent the exact agreement between the "GOLD" standard reference (DG30) and the method under test. Gray areas represent disagreement between the diagnostic methods, and false positive results are placed above the dashed diagonal line, while false negatives are below this line. The level of agreement (Kappa) and its variation (CI 95\%) between the diagnostic method performed on DG20 and the standard reference (DG30) are also shown in Figure 2A and Figure 2B.
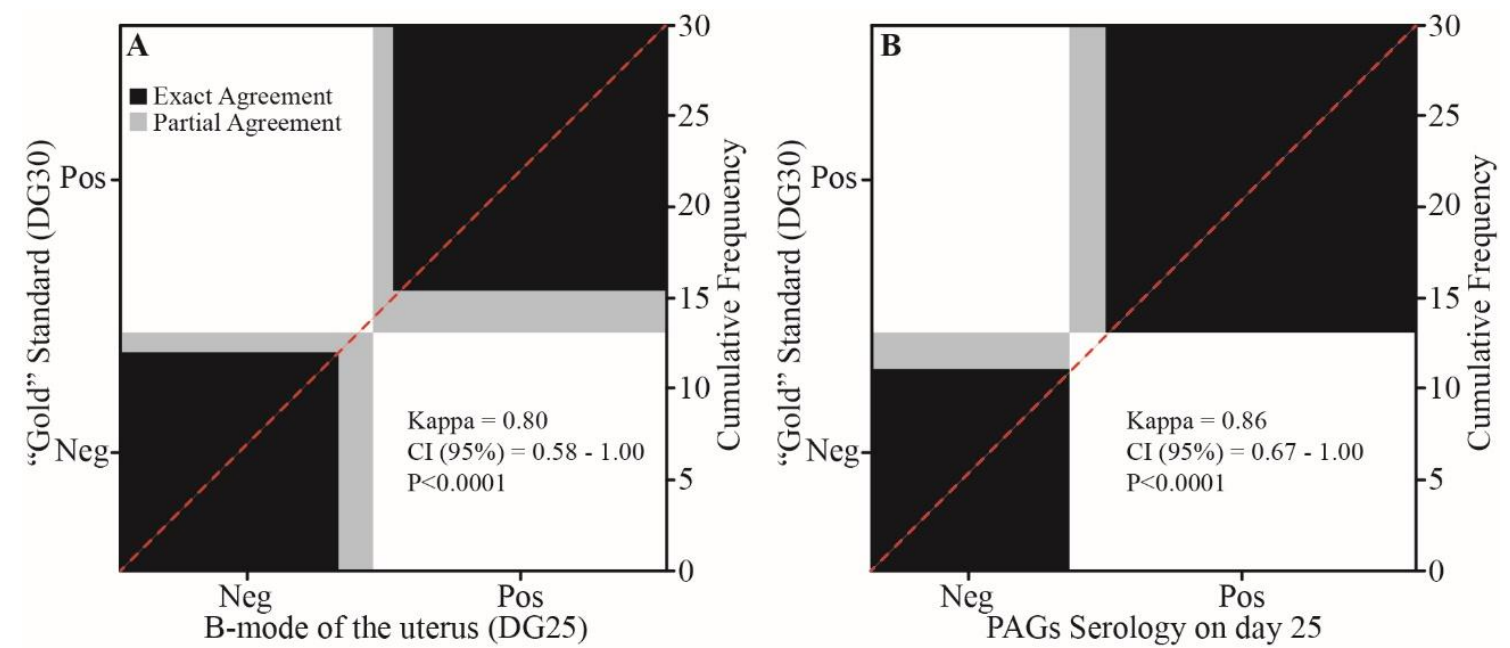

Figure 3. Correlation chart of the pregnancy diagnosis based on visualization of the embryonic vesicle (Figure 3A) and PAGs serology (Figure 2B) performed on day 25 (DG25) of the expected pregnancy of bovine embryo recipients. In each chart, the black squares represent the exact agreement between "GOLD" standard reference (DG30) and the method under test. Gray areas represent disagreement between the diagnostic methods, and false positive results are placed above the dashed diagonal line while false negatives are below this line. The level of agreement (Kappa) and its variation (CI 95\%) between the diagnostic method performed on DG25 and the standard reference (DG30) are also shown in Figure 3A and Figure 3B.

In trial 3, when held at 30 days of gestation, pregnancy check based on serologic detection of PAGs also presented $100 \%$ of sensitivity and high agreement $(\mathrm{k}=0.82, \mathrm{P}<0.0001)$ with the ultrasound gold standard. The test showed no false negative results; however, false positives were observed in 4 diagnoses (Figure 4). 


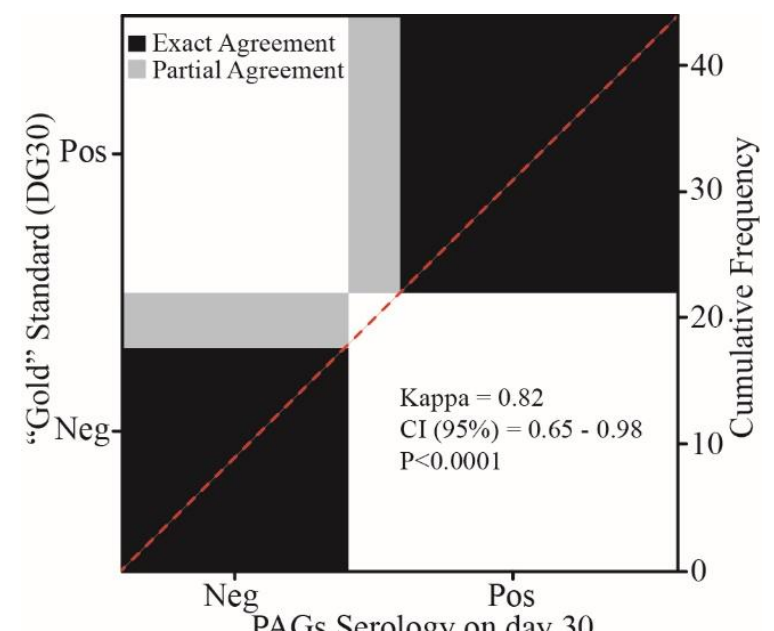

Figure 4. Correlation chart of the pregnancy diagnosis based on PAGs serology performed on day 30 of the expected pregnancy of bovine embryo recipients. In each chart, the black squares represent the exact agreement between "GOLD" standard reference (DG30) and the method under test. Gray forms represent disagreement between the diagnostic methods, and false positive results are placed above the dashed diagonal line, while false negatives are below this line. The level of agreement (Kappa) and its variation (CI 95\%) between the Serology performed on day 30 and the standard reference (DG30) are also shown in Figure 4.

\section{DISCUSSION}

This study combined ultrasonography and a serological diagnostic method in order to increase the accuracy of early pregnancy detection in cattle performed up to $30 \mathrm{~d}$ after estrous. The ultrasound examination has high accuracy for this diagnosis, especially after the 28 days (Quintela et al., 2012). However, with the progressive improvement in the quality and resolution of ultrasound equipment, and the recent introduction of Color Doppler technology to access CL functionality (Ginther et al., 2009; Siqueira et al., 2013; Guimarães et al., 2015), the tendency is to decrease this threshold.

The pregnancy diagnosis based on CL blood flow, when performed on day 20 of the expected pregnancy post -AI (Siqueira et al., 2013) or -ET (Guimaraes et al., 2015) has a great use potential, especially for the detection of nonpregnancy. However, the specificity of this test is affected by the occurrence of irregular (long or short) CL lifespan, and by early embryonic loss. In the first trial, this diagnostic method proved its high sensitivity $(100 \%)$, with no false negative results, even though the specificity was only moderate $(53.3 \%)$. In this case, the low $(34.8 \%$, $16 / 46$ ) conception rate may have been associated with embryonic losses after maternal recognition, and thus with a higher incidence of prolonged cycles. The attempt to reduce false positive results $(46.7 \%, 14 / 30)$ by including PAGs serology was not successful. On this gestational age, the low sensitivity of the test to detect positive animals partially rejects our hypothesis, and it did not contribute to improve overall accuracy of the color Doppler method (69.6\%).

The embryonic vesicle and the embryo itself can be detected with ultrasound as soon as 18.5 (Totey et al., 1991) or 20.3 (Curran et al., 1986) days of gestation. However, when performed too early, this method has limited accuracy due to anatomical differences, volume of liquids and its concentration in specific segments of the uterine horn. Thus, this diagnostic approach is not practical when performed before 26-28 days of gestation (Pieterse et al., 1990; Romano et al., 2006; Quintela et al., 2012). In this study, the examination was performed on day 25 and the sensitivity of $88.2 \%$ was due to 2 false negative results. Safe detection of non-pregnant animals is the major concern of early pregnancy diagnosis, since animals can be quickly re-synchronized. At this gestational age, PAGs inspection contributed to improve the accuracy of ultrasound examination (from 90.0 to $96.7 \%$ ), which is in agreement with our hypothesis. The considerable increase in maternal concentration of PAGs that 
occur between days 22 to 24 of gestation (Green et al., 2005) is probably responsible for the elevation of the sensitivity of the test from $6.3 \%$ (DG20) to $100 \%$, i.e., when performed 5 days later. Thus, the serologic exam allows false negative results from $\mathrm{B}$-mode ultrasound to be detected.

According to the manufacturer, serological detection of the PAGs gives $98-99 \%$ of true positive (pregnant), with $1-5 \%$ of false positive results, when samples are taken from D28. In this study, when samples were held 3 days before recommended (DG25) or on day 30 (DG30), the overall accuracy of this diagnostic method was 93.3 or $90.9 \%$, respectively. The true positive value was 84.5 and $89.5 \%$, with $6.7(2 / 30)$ and $9.1 \%(4 / 44)$ of false positive results for DG25 and DG30, respectively.

Early embryonic loss (EEL) can be caused by a number of factors that take place until $28 \mathrm{~d}$ of gestation (Diskin and Morris, 2008), and its incidence can reache 20 to $40 \%$ (Santos et al., 2009). Once established the relationship between trophoblast and endometrium, gestational glycoproteins are released into maternal bloodstream with half-life of 4.3 to 8.4 day (Green et al., 2005). Therefore, the incidence of false positive results with serological detection of PAGs is directly influenced by the rate of EEL, which disturbs the positive predictive value of the test. In this study, the rate of EEL was not evaluated, however, during the ultrasound evaluations, reduced uterine content associated to the lack of an embryo in recipients with false positive results $(n=4)$ in the serological test, performed on DG30 was observed. These observations, combined with the presence of corpus luteum, may suggest recent embryo loss.

\section{CONCLUSIONS}

The PAGs serology did not contribute to reduce the incidence of false positive results, when associated to color Doppler ultrasound on DG20. However, the high sensitivity $(100 \%)$ of the test when performed from day 25 (DG25 and DG30) can reduce the incidence of false negative diagnosis, when associated to the use of B-mode ultrasound examination on day 25. Regardless of the method, the occurrence of embryonic loss can affect the results of the diagnosis, mainly for the specificity of serological examination.

\section{ACKNOWLEDGEMENT}

The authors thank the Fundação de Amparo à Pesquisa do Estado de Minas Gerais (FAPEMIG), Conselho Nacional de Desenvolvimento Científico e Tecnológico (CNPq), Coordenação de Aperfeiçoamento de Pessoal de Nível Superior (CAPES, PROCAD 2013) for the financial support, and FMVZ/USP, UNIFENAS and Biotran LTDA for technical support.

\section{REFERENCES}

BEAL, W.E.; PERRY, R.C.; CORAH, L.R. The use of ultrasound in monitoring reproductive physiology of beef cattle. J. Anim. Sci., v.70, p.924-929, 1992.

CONSTANT, F.; CAMOUS, S.; CHAVATTEPALMER, P. et al. Altered secretion of Pregnancy Associated Glycoproteins during gestation in bovine somatic clones. Theriogenology, v.76, p.1006-1021, 2011.

CORDOBA, M.; SARTORI, R.; FRICKE, P. Assessment of a commercially available early conception factor (ECF) test for determining pregnancy status of dairy cattle. J. Dairy Sci., v.84, p.1884-1889, 2001.

CURRAN, S.; PIERSON, R.A.; GINTHER O.J. Ultrasonographic appearance of the bovine conceptus from days 20 through 60. J. Am. Vet. Med. Assoc., v.189, p.1295-1302, 1986.

DISKIN, M.; PARR, M.; MORRIS, D. Embryo death in cattle: an update. Reprod. Fertil. Devel., v.24, p.244-251, 2012.

DISKIN, M.G.; MORRIS, D.G. Embryonic and early foetal losses in cattle and other ruminants. Reprod. Dom. Anim., v.43, p.260267, 2008.

GINTHER, O.J.; ARAUJO, R.R.; PALHÃO, M.P. et al. Necessity of sequential pulses of Prostaglandin f2alpha for complete physiologic luteolysis in cattle. Biol. Reprod., v.80, p.641648, 2009.

GREEN, J.A.; PARKS, T.E.; AVALLE, M.P. et al. The establishment of an ELISA for the detection of pregnancy-associated glycoproteins (PAGs) in the serum of pregnant cows and heifers. Theriogenology, v.63, p.1481-1503, 2005. 
GUIMARÃES， C.R.B.; OLIVEIRA， M.E.; ROSSI, J.R. et al. Corpus luteum blood flow evaluation on Day 21 to improve the management of embryo recipient herds. Theriogenology, v.84, p.237-241, 2015.

HOLDSWORTH, R.J.; HEAP, R.B.; BOOTH, J.M. et al. A rapid direct radioimmunoassay for the measurement of oestrone sulphate in the milk of dairy cows and its use in pregnancy diagnosis. J. Endocrinol., v.95, p.7-12, 1982.

LUCY, M.; GREEN, J.; POOCK, S. Pregnancy determination in cattle: a review of available Alternatives. In APPLIED REPRODUCTIVE STRATEGIES IN BEEF CATTLE, 2011, Joplin. Proceedings... Joplin: [ARSBC], 2011. p.367376.

PIETERSE, M.C.; SZENCI, O.; WILLEMSE, A.H. et al. Early pregnancy diagnosis in cattle by means of Linear-Array Real-Time ultrasound scanning of the uterus and a quantitative and qualitative milk progesterone test. Theriogenology, v.33, p.697-707, 1990.

POHLER, K.G.; GREEN, J.A.; GEARY, T.W. et al. Predicting embryo presence and viability. Adv. Anat. Embryol. Cell Biol., v.216, p.253-270, 2015.

POHLER, K.G.; PEREIRA, M.H.; LOPES, F.R. Circulating concentrations of bovine pregnancyassociated glycoproteins and late embryonic mortality in lactating dairy herds. J. Dairy Sci., v.99, p.1584-1594, 2016 b.
POHLER, K.G.; PERES, R.F.; GREEN, J.A. et al. Use of bovine pregnancy associated glycoproteins (bPAGs) to diagnose pregnancy and predict late embryonic mortality in postpartum Nelore beef cows. Theriogenology, v.85, p.1652-1659, 2016a.

QUINTELA, L.A.; BARRIO, M.; PEÑA, A.I. t al. Use of ultrasound in the reproductive management of dairy cattle. Reprod. Domest. Anim., v.47, p.34-44, 2012.

ROMANO, J.E.; THOMPSOM, J.A.; FORREST, D.W. et al. Early pregnancy diagnosis by transrectal ultrasonography in dairy cattle. Theriogenology, v.66, p.1034-1041, 2006.

SANTOS, J.E.P.; RUTIGLIANO, H.M.; FILHO, M.F.S. Risk factors for resumption of postpartum estrous cycles and embryonic survival in lactating dairy cows. Anim. Reprod. Sci., v.110, p.207-221, 2009.

SIQUEIRA, L.G.; AREAS, V.S.; GHETTI, A.M. et al. Color Doppler flow imaging for early detection of non-pregnant cattle at 20 days after timed artificial insemination. J. Dairy Sci., v.96, p.6461-6472, 2013.

TOTEY, S.M.; SINGH, G.; TANEJA, M. et al. Ultrasonography for detection of early pregnancy following embryo transfer in unknown breed of Bos indicus cows. Theriogenology, v.35, p.487497, 1991. 